\title{
A Construção das Redes Sociais de Operadores de ONGs: Os Mecanismos de Recrutamento a Partir das Relés Sociais
}

\author{
Breno Augusto Souto Maior Fontes - Universidade Federal de Pernambuco ${ }^{1}$
}

\begin{abstract}
Resumo
Pretendemos, neste artigo, investigar os processos subjacentes às trajetórias os operadores de ONGs: como são recrutados, quais seus campos de filiação institucional mais freqüentes, que características mais significativas podem ser destacadas neste processo. Trata-se, de um lado, de desvelar o mecanismo de formação das redes sociais destes atores; de outro, investigar as suas diversas inserções em campos de sociabilidade. A partir de um estudo empírico de operadores de Organizações Não Governamentais que atuam na área de Educação na Região Metropolitana do Recife procedemos à reconstrução de suas trajetórias de sociabilidade.
\end{abstract}

Palavras chave: Rede Social, Relé Social, Associações Voluntárias.

\begin{abstract}
The following article investigates certain processes that undergo the professional trajectory of NGOs officials: how they are recruited, what are their most common institutional fields of affiliation, what significant features could be identified in these processes. Our aim here is twofold: on the one hand, to reveal the mechanisms which account for the formation of these actors social networks. On the other hand, we investigate their different insertions in fields of sociability. The concept of social relais - here understood as a mechanism that produces and disseminates the mobilization of individuals from constituted to new networks, creating networks of networks - is used in the analysis of information about NGOs officials working in the field of education in the Metropolitan Region of Recife.
\end{abstract}

Key words: Social Networks, Social relais, Voluntary Associations.

\section{I ntrodução}

Pretendemos, neste artigo, investigar os processos subjacentes às trajetórias os operadores de ONGs: como são recrutados, quais seus campos de filiação institucional mais freqüentes, que características mais significativas podem ser destacadas neste processo. Trata-se, de um lado, de desvelar o mecanismo de formação das redes sociais destes atores; de outro, a partir do conceito de relé, as diversas inserções em campos de sociabilidade, localizados institucionalmente ou não, destes atores.

\footnotetext{
${ }^{1}$ Enviar correspondencia a: brenofontes@gmail.com. Agradeço ao Prof. Klaus Eichner, da Universidade de Hamburgo, Alemanha, por sua valorosa contribuição no tratamento dos dados estatísticos
} 
As diversas pesquisas sobre Organizações não governamentais e práticas associacionistas têm destacado a importância deste fenômeno, ao mesmo tempo em que revelando os seus mecanismos de formação. Há, entretanto, uma grande lacuna nestes estudos: uma relativa imprecisão ou mesmo ausência de referências a processos explicativos das trajetórias de sociabilidades destes atores, das diversas inserções institucionais vivenciadas em suas biografias que estão conectadas formando uma imensa teia cujos mecanismos são imprescindíveis para a compreensão do fenômeno associativo. A estrutura de redes sociais resultantes deste complexo processo - em campos de sociabilidade específicos - nos permite compreender com mais acuidade o fenômeno das Organizações Sociais.

A partir de um estudo empírico de operadores de Organizações Não Governamentais que atuam na área de Educação na Região Metropolitana do Recife procedemos à reconstrução das trajetórias de sociabilidade de operadores de ONGs da Região Metropolitana do Recife ligadas à área de Educação. O campo profissional educação foi o escolhido por concentrar um número importante de ONGs na Região, com Instituições diversas - uma variedade importante de desenhos organizacionais - e uma amplitude significativa de conexões com outros atores da sociedade (Instituições de Cooperação Internacional, Movimentos Sociais, Agências Públicas, Igrejas, entre outros). O nosso interesse não se dirige especificamente para o campo profissional destas instituições. Nem mesmo as Instituições são o foco principal de análise. O que nos interessa, de um lado, é verificar como são formadas as redes de sociabilidade dos operadores das ONGs, de um lado; e como, por outro, como as relés são ativadas para o recrutamento destes operadores. 0 campo Institucional é o palco onde estes processos estão localizados e as referências para as medidas de redes que utilizaremos são principalmente as ONGs - não somente aquelas onde os entrevistados trabalham - mas também Igrejas, Partidos Políticos, Agências de Cooperação Internacional2. Que simplesmente reflete as práticas de sociabilidade de seus membros, que constroem conexões complexas com outros atores da sociedade.

\footnotetext{
${ }^{2}$ Foram entrevistadas 94 pessoas que trabalham em 10 ONGs, atuando na Região Metropolitana do Recife na área de Educação. Estas pessoas citaram 204 Instituições, que constituem a rede dos entrevistados. Todas as Instituições citadas estão ligadas diretamente à atividade profissional destes entrevistados, que estabelecem conexões na maior parte das vezes profissionais (para, por exemplo, levar a cabo projetos ou mesmo fazendo parte de sua trajetória profissional), mas também conexões com pessoas de seu círculo pessoal que estão envolvidas em atividades ligadas ao campo profissional do entrevistado (aqui, pessoas que trabalham juntas, ou que o entrevistado conheceu em outro círculo social e as introduziu em alguma ONG)
} 
O texto está organizado em três partes, além desta introdutória: (a) Uma revisão da literatura sobre relés sociais. A expressão "relé social" , como veremos, foi utilizada por Olhemacher para instrumentalizar empiricamente um estudo sobre mobilização coletiva na Alemanha. Não encontramos registro deste conceito na literatura. Entretanto, a idéia que esta palavra veicula tem inúmeras referências principalmente em estudos sobre mobilização coletiva e práticas associativas. A partir do conceito de Olhemacher construiremos algumas questões que serão objeto de investigação empírica. (b) As trajetórias de sociabilidade dos operadores de ONGs. Nesta parte, ensaiaremos uma desconstrução das redes a partir das relés. Colocaremos em evidência os processos subjacentes à estruturação das relés para testarmos duas hipóteses: que existem, em primeiro lugar Instituições que são o campo privilegiado para a formação de relés sociais; que o desenho das redes social é estratégico para compreender o processo de mobilização de recursos, não somente os de natureza financeira, mas também os oriundos do que a literatura comumente designa de "capital humano". Quer dizer, que um dos principais mecanismos de recrutamento de profissionais para as ONGs são os contatos estabelecidos entre os que ingressam e aqueles que já estão lá inseridos. Os campos institucionais de recrutamento são exatamente as relés. (c) Finalmente, temos as conclusões, onde colocaremos algumas questões remetendo a reflexão à possibilidade de se pensar em processos que possam ser generalizados, para além da referência empírica direta onde foram constatados. Quer dizer, se os mecanismos de formação de relés poderiam obedecer a alguma generalidade; ou se haveria entre o campo institucional das ONGs alguma particularidade que o distinguisse de outros, como por exemplo, o campo das organizações mercantis ou do Estado.

\section{As Relés Sociais ${ }^{3}$}

O fenômeno "relé social", grosso modo, pode ser descrito como o mecanismo que produz e divulga a mobilização dos indivíduos para novas redes, criando-se desta forma "redes de redes". Quer dizer, a partir de laços sociais pré-existentes, acessamos pessoas e nos inserimos em outras localizações institucionais no nosso espaço de sociabilidade.

\footnotetext{
3 Esta parte se inspira fortemente em artigo publicado pelo autor e Sabina Stelzig. Consultar na Bibliografia: (Fontes, 2004).
} 
O conceito de relé social é tomado emprestado de Ohlemacher, que introduz esta idéia enquanto instrumento para explicar processos de mobilização e recrutamento de militantes de movimentos sociais. É empregado neste caso enquanto instrumento analítico para explicar, a partir das redes egocentradas, os processos de mobilização subjacentes a um movimento social. Os relés sociais produzem e divulgam a mobilização para novas redes; através deles são criadas novas "redes de redes". Em relação ao movimento pacifista dos anos 80 na Europa Ocidental, por exemplo, temos as Igrejas como relés sociais e em relação ao movimento feminista, as Universidades. "O termo relé é empregado como alternativa ao termo "broker" que é definido por Boissevain como" aquele que recodifica e seleciona um novo canal, codificando e transmitindo para o seguinte, ligando o ator em uma trilha de novas sociabilidades"4.

Grosso modo, relés sociais são redes que funcionam como contexto para relações face a face ${ }^{5}$ São as seguintes as funções dos relés sociais:

1. Eles ligam redes não conectadas anteriormente. Quer dizer, eles atuam enquanto "brokers" entre estrangeiros ou grupos de estrangeiros. Pessoas entram em contato com outras através de "pontes" estabelecidas a partir de contatos sociais pré-existentes. Seria o caso, por exemplo, de ser apresentado em uma reunião social a uma pessoa, e esta me introduzir em seu círculo social. Aqui o conceito de círculo social em Simmel é bastante útil para a compreensão desta característica de relé social. Ultrapassando as fronteiras de sociabilidades primárias, o indivíduo na modernidade tende a ver estabelecidos os laços sociais preponderantemente a partir de contatos de natureza associativa, quer dizer, instrumentalizados em objetivos mais estreitos que aqueles fundados na amizade ou no parentesco. Os círculos sociais ampliados seriam acompanhados do crescimento da liberdade: "o laço não é abolido, mas com quem ou de que forma vem a ser uma questão de escolha" (Simmel, 1999:409). A natureza de elegibilidade dos círculos não impede, entretanto, a construção de redes relativamente adequada à posição do ator na estrutura social; na verdade, é um dispositivo que poderíamos qualificar de funcional, na medida em que reafirma o

\footnotetext{
${ }^{4}$ Boissevain, Jeremy: Friends of Friends. Networks, manipulators and coalition. Oxford, Blackwell, 1976, p. 152)

5 Consultar a este respeito Thomas Ohlemacher "Brücken der mobilisierung. Soziale Relais und persönliche Netzwerke in Bürgerinitiativen gegen militärischen tie flug"; e também, do mesmo autor, "Struktur und System. Eine Empiriebasierte Annäherung von Strukturaler Analyse und Systemtheorie". Habilitationsschrift na der Universität Hamburg, 1999, p.68 e ss).
} 
status e instrumentaliza de forma mais eficiente os recursos decorrentes de sua posição social ${ }^{6}$. Simmel (1999:415), por exemplo, exemplifica esta natureza de os círculos sociais serem elegíveis (quer dizer, decorrentes da liberdade de escolha do ator) e ao mesmo tempo rígidos, decorrente da posição dos atores na estrutura social:

$\mathrm{Na}$ Idade Média, alguns círculos menos individuais permitiram à pessoa pertencer a círculos típicos, para além de seu status de burguês de uma cidade". As ligas Hanseáticas eram alianças de cidades e permitiam ao indivíduo fazer parte de um círculo de atividades que não somente ultrapassava cada cidade em particular, mas as fronteiras do Império; as corporações não davam conta da complexa articulação jurídica entre as cidades, mas integravam o indivíduo para além de seu status de burguês, em associações que se estendiam por toda a Alemanha.

2. Eles formam um ambiente, a organização e a estrutura institucional de um grande número de relações face a face. Os relés se estruturam basicamente através de círculos sociais que entrecruzam processos de sociabilidades originários de redes egocentradas. Isto quer dizer que o campo originário é o reflexo das estruturações das práticas localizadas em vários espaços institucionais, decorrentes da especialização funcional dos processos de sociabilidade de indivíduos que vivem em sociedades complexas. Nem todos os espaços institucionais, entretanto, têm a mesma importância no que diz respeito à formação de campos adequados ao alavancamento de relés. Aqueles mais adequados às interações secundárias são os que mais se servem para originar oportunidades de acessos a novas redes.

3. Algumas destas redes (redes de mediação) geram novas redes (subredes) e ao mesmo tempo renovam o conteúdo das redes antigas (redes de procedência); uma rede de mediação, por exemplo, a Igreja para o caso do movimento pacifista, ao ser origem principal na formação de um novo campo institucional conseqüentemente com um grande numero de atores sociais em situações multiplexas ${ }^{7}$ relativamente às inserções de sociabilidade - pode ter o seu processo de filiação de novos membros alterado, na medida em que as redes de procedência tenham uma forte influência destes atores envolvidos no movimento pacifista. A relação entre as redes de mediação, de procedência e as novas inserções

\footnotetext{
${ }^{6}$ Há, é certo, espaços de escolhas estratégicas do ator, o que explica porque alguns alavancam recursos de maneira mais eficiente que outros, mesmo estando posicionados em igualdade na estrutura social.

${ }^{7} \mathrm{O}$ conceito de multiplexidade remete á idéia de localizações múltiplas. Assim, "uma relaçao é multiplexa quando há acontece múltiplas transações, quer dizer, quando há um crescimento de parceiros. Assim, o índice de multiplexidade é dado a partir da seguinte relação: $m=n / p$, onde $n$ e o número total de trocas e p o número de pares que estão em relação em pelo menos uma troca. (Forsé,1999:46).
} 
institucionais é um ingrediente importante para a compreensão dos processos de recrutamento de ativistas sociais, como veremos mais adiante.

4. A mobilização em um relé social ultrapassa as fronteiras do próprio relé. Quer dizer, se se considera o início do processo as articulações entre as redes de sociabilidade dos atores sociais, localizando um campo particular como aquele onde se concentra o encontro de sujeitos sociais articulados em um propósito comum para a ação coletiva (para o caso dos movimentos sociais), ou simplesmente para o estabelecimento de práticas compartilhadas (como por exemplo, a fundação de clubes recreativos ou de grêmios literários), estes novos campos institucionais não tem por origem exclusiva as redes de mediação, os relés sociais. Também devem ser considerados outros elementos importantes para a construção de práticas de sociabilidade, inclusive aquelas localizadas fora das relés. Poderíamos pensar, por exemplo, no fato de que o campo institucional recém criado estabelece mecanismos próprios de atração de novos participantes, através de pontes entre atores lá inseridos e outros localizados nas redes egocentradas, não necessariamente incluídos em campos institucionais comuns. Pode-se, por exemplo, pensar, que os indivíduos "a", "b" e "c" introduzam " $x$ " " $y$ " e " $z$ ", sem que haja necessariamente uma interconexão entre estes novos atores. Quer dizer, não se pode falar em um campo institucional que tenha atuado enquanto rede de mediação, mas simplesmente de redes de procedência de atores que não se articulam entre si. Também outros mecanismos de recrutamento podem ser pensados, como por exemplo, a propaganda, os efeitos de demonstração resultantes da impressão causada à opinião pública das ações do movimento, etc. O que se quer afirmar é simplesmente que os mecanismos das redes, principalmente aqueles de relé social, são importantes ingredientes para a explicação dos processos de mobilização e recrutamento de atores.

Os relés sociais, por sua vez, apresentam as seguintes características estruturais:

1. Eles têm de estar abertos a uma variedade de valores, experiências e a várias conjunturas sócio-estruturais. Assim, eles conseguem atingir um elevado grau de heterogeneidade em sua composição (o mesmo vale para conjunturas políticas e culturais, situações sócio-estruturais e experiências individuais), já que quanto maior o grau de heterogeneidade, maior a capacidade do relé social de ligar pessoas e redes anteriormente não conectadas. Quanto maior o grau de heterogeneidade das pessoas na rede, maior o grau de diversidade e, com isso, maior o potencial de expansão da rede a partir de um relé. Por isso, a fim de funcionar como um relé, os contatos das redes devem estar bem estabelecidos na 
sociedade. Aqui, novamente, a idéia Simmel sobre características específicas de afiliações a grupos na modernidade, é central para a compreensão deste processo. Para Simmel ${ }^{8}$, grupos sociais inseridos em um contexto sócio-histórico da modernidade são marcadamente estruturados a partir de critérios de elegibilidade de seus participantes. Há, de um lado, dada a crescente complexidade social, uma diversidade de orientação de valores bastante intensa; de outro, e de certa forma resultante da assertiva anterior, uma possibilidade maior de se elegerem filiações institucionais e padrões de sociabilidade mais adequados aos gostos individuais. 0 que significa dizer que estes espaços de sociabilidade são altamente heterogêneos, proporcionando desta forma a conexão de redes em combinações diversas. Os padrões de sociabilidade, desta forma, são fortemente móveis e instáveis (diferentemente, por exemplo, dos padrões das sociedades tradicionais, onde há certa rigidez estrutural no que diz respeito às oportunidades de novos contatos ou experiências de sociabilidade, para além dos grupos tradicionalmente organizados).

2. Algumas dessas subredes, no contexto de diferentes contatos face a face, podem gerar novas redes, como por exemplo, um grupo de protesto. Esta subrede deve apresentar um elevado grau de homogeneidade em relação ao conjunto do relé. Esta é uma característica de processos de mobilização coletiva bastante conhecida dos que trabalham com a Teoria da Mobilização de Recursos. $O$ fato de que 0 recrutamento de novos militantes se dê a partir de contatos face a face é observado em diversos contextos ${ }^{9}$. Indivíduos que são mobilizados a partir de redes egocentradas (muitas vezes, mas não preponderantemente, em inserções de laços de sociabilidade primários) são lançados em campos institucionais onde freqüentemente diversidade de origens e trajetórias é bastante intensa; o que garante, de um lado, uma intensa heterogeneidade no conjunto deste campo de sociabilidade, mas ao mesmo tempo sub-redes bastante homogêneas, posto que resultem de situações de recrutamento onde os padrões de sociabilidade são caracteristicamente primários.

3. A fim de poder ligar a heterogeneidade do relé com a homogeneidade da subrede, é necessário uma variedade de relações fracas ("weak ties"). Uma extensa mobilização, por sua vez, precisa de muitos laços fracos para: a) ligar a subrede com o conjunto do relé; e b) para a ligação com a sociedade e, assim, conseguir um contato com um potencial máximo de mobilização.

\footnotetext{
${ }^{8}$ Consultar, a respeito, Pescosolido(2002) e Coser (1965).

${ }^{9}$ Ver mais adiante sobre a teoria de mobilização de recursos.
} 
Ao analisar os relés sociais, o nível microestrutural (as relações entre contatos privados) não é o principal, mas sim o nível mesoestrutural. Interessa-nos quem conhece quem através de qual grupo. É interessante verificar como, por exemplo, dentro da estrutura de redes sociais das pessoas filiadas institucionalmente às associações voluntárias se processa a formação das relés sociais existentes nesta rede social. A estrutura das redes sociais dos atores participantes das associações voluntárias indica as principais relés, que instrumentalizam o acesso destas pessoas a outros grupos ou Instituições. Estas "cadeias" transmissoras de sociabilidade indicariam o volume de capital social disponível, o que, por sua vez, irá se refletir nas oportunidades de alocação de recursos.

\section{As práticas associativas explicadas a partir do conceito de rele social}

O conceito de relé social pode ser pensado enquanto instrumento para o esclarecimento de diversos processos sociais. Interessa-nos particularmente trabalhar este conceito para a investigação empírica dos processos subjacentes às práticas associativas. Vale salientar que o conceito de relé, embora não seja muito utilizado, remete a uma série de fenômenos relativamente bem comentados na literatura das ciências sociais. No que diz respeito às práticas associativas, importa assinalar que, embora possamos considerar diversas teorias que tratem do assunto e que não remetam à teoria das redes sociais, muitas das questões abordadas são também passíveis de serem compreendidas pela idéia de redes. Mais ainda, que a teoria das redes sociais - no nosso caso, especificamente o conceito de relés promete ser um poderoso auxiliar nos processos explicativos de como as pessoas são mobilizadas para participar em associações voluntárias. Neste caso, o recrutamento é movido principalmente pela "apresentação" do indivíduo a uma associação voluntária. Este indivíduo, que está localizado em um campo institucional qualquer, é levado a conhecer uma associação voluntária através de uma pessoa que faz parte de sua rede. Dentre os inúmeros casos de explicação de recrutamento, este é relativamente pouco comentado. Embora a literatura não trate diretamente dos processos de recrutamento via redes, há uma extensa referência a este processo, e mesmo não nomeando mecanismos explicativos subordinados à idéia de rede, podemos identificar várias questões que são importantes para a análise:

1. Considere-se, por exemplo, a teoria de mobilização de recursos, que "enfatiza a importância de fatores estruturais tais como a disponibilidade de recursos para a ação coletiva" (Klandermans 1984:583-600). Aqui há claramente um 
privilegiamento de fatores como recursos a serem disponibilizados e estratégias dos atores para alocá-los ${ }^{10}$ Não indica, entretanto, que muitos destes recursos se tornam acessíveis a partir das redes sociais dos atores considerados. I déias como "frame mobilization"11 (que indica a seqüência de fluxos estáveis e previsíveis de comunicação entre atores que tendem a se organizar em torno de motivos razoáveis para a constituição da ação coletiva), ou a de "political opportunity", que mostra a existência de condições favoráveis à mobilização política - visibilidade e legitimidade da causa, posição relativamente empoderada do movimento, etcdescrevem com relativo sucesso processos de mobilização para a ação coletiva, mas não explicam como estas janelas de oportunidades são abertas. Como, por exemplo, fluxos comunicativos são mais densos em um ambiente de sociabilidade que outro? Que significa exatamente oportunidades políticas? Qual a dimensão distributiva destas oportunidades? (pensando, por exemplo, que haja uma desigualdade na distribuição de recursos de comunicação e de oportunidade para ação, que esta desigualdade se explique principalmente à luz de fatores de ordem estrutural; que, dentre estes fatores, há o componente do desenho das redes sociais).

2. Há, também, entre os estudiosos, o consenso de que as mobilizações coletivas não se seguem de maneira estável e uniforme. Há um fluxo e refluxo, momentos de ápice e outros de desmobilização. O problema dos ciclos de protesto ${ }^{12}$ aproximase, de um lado daquele relativo às redes de mobilização na medida em que as estratégias de mobilização de recursos e de recrutamento de novos militantes apóiam-se fortemente nas redes dos participantes. Nestas estruturações das redes, o mecanismo de relés sociais é fundamental, na medida em permite a análise dinâmica do processo (os diversos canais de comunicação estabelecidos entre as redes de origem, de mediação e de destino), conseqüentemente das diversas fases de um processo de mobilização coletiva.

3. Uma outra questão muito discutida diz respeito à busca de explicações sobre como as pessoas são recrutadas para o movimento. À parte as explicações mais de natureza psicológica, diversos autores enfatizam o componente estrutural do processo (sem, entretanto, esquecer da relativa independência do ator que, diante de opções, escolhe a mais adequada, a que Ihe seja mais satisfatória no que diz

\footnotetext{
${ }^{10}$ Remetendo, conseqüentemente à teoria da escolha racional.

${ }^{11}$ Consultar Diani (1978).

12 Sobre ciclos de protesto, consultar Oliver (2000).
} 
respeito à relação entre os custos e benefícios da ação). McAdam (1986), por exemplo, quando analisa o processo de recrutamento em uma mobilização coletiva nos Estados Unidos, enumera como fatores indispensáveis à compreensão do processo, de um lado, os fatores individuais - diretamente ligados ao cálculo da relação custo/benefícios da ação; por outro, fatores estruturais, que "puxam" o ator para ação: “(a) grande número de afiliações organizacionais; (b) maiores níveis de atividades ligadas principalmente a direitos civis; (c) laços mais fortes e intensos". Por sua vez, Snow (1980) afirma que os processos de recrutamento são fortemente influenciados pela "proximidade estrutural, disponibilidade e interações afetivas entre os membros do movimento". O que indica que os processos de recrutamento são fortemente influenciados pelas redes dos militantes, que trazem para 0 movimento novos membros. A relação entre os processos de recrutamento de novos membros e as redes dos participantes dos movimentos é um fenômeno que encontra evidência empírica em diversos estudos ${ }^{13}$, inclusive em alguns deles mostrando que a função de recrutamento é apenas uma dentre outras também importantes exercidas em estruturações de sociabilidades das redes sociais dos participantes de uma ação coletiva. Passy (2000), por exemplo, afirma que "redes têm múltiplas funções no processo que resulta na participação em ações coletivas. Redes socializam e constroem identidades individuais (função socializadora), oferecem aos indivíduos que são culturalmente sensíveis a questões políticas mais específicas oportunidades para participarem (função de recrutamento), e moldam preferências individuais antes de os indivíduos decidirem juntar-se a um movimento (função de moldar decisões de atores)". Estes autores citam e enfatizam a importância de se considerar o fenômeno de redes sociais. Não trabalham, entretanto, o conceito. Os modelos de análise empírica não consideram a instrumentalização do conceito, que é referido antes como um recorte a ser aprofundado que propriamente um componente da argumentação baseada em fatos empíricos.

Podemos, desta forma, constatar que o fenômeno de redes é bastante visível na literatura sobre associações voluntárias, mesmo se não explicitamente analisado. A sua importância é ressaltada, inclusive em alguns momentos colocando-se quase como conditio sine qua non, como é o caso onde Scherrer-Warren (1996) afirma que "os movimentos não se organizam apenas devido a interesses e oportunidades, mas também devido à existência de redes sociais"; ou mesmo na opinião de

13 Consultar, a este respeito, Melucci (1996), Sampell (1998), Baron (1997). 
Melucci (1996), o fato de que os movimentos em sociedades complexas serem desdobramentos de "redes subterrâneas de grupos de encontro e circuitos de solidariedade".

\section{Os mecanismos de recrutamento a partir das relés ${ }^{14}$}

A rede de operadores de ONGs que pesquisamos está representada graficamente no quadro 1. Esta rede é composta por Organizações citadas pelos entrevistados, sendo portanto mais ampla que seus lugares de filiação institucional. São Instituições onde os entrevistados mantêm de alguma maneira uma ligação: locais de trabalho, atual ou passado, Instituições onde trabalham pessoas conhecidas dos entrevistados, Instituições que têm algum relacionamento com aquelas onde o entrevistado trabalha. Em resumo, esta rede, composta de 204 Instituições, significa o campo de sociabilidade onde os entrevistados se inscrevem. Interessanos, neste estudo, analisar os mecanismos de recrutamento dos operadores de ONGs. Este fenômeno vai ser investigado a partir do campo de sociabilidade específico, o de ONGs atuando em educação. A partir destas ONGs (onde trabalham os entrevistados), reconstruiremos as trajetórias de filiação dos operadores de ONGs, explicando seus mecanismos a partir das idéias de redes de procedência e de mediação, descritas na segunda parte deste artigo.

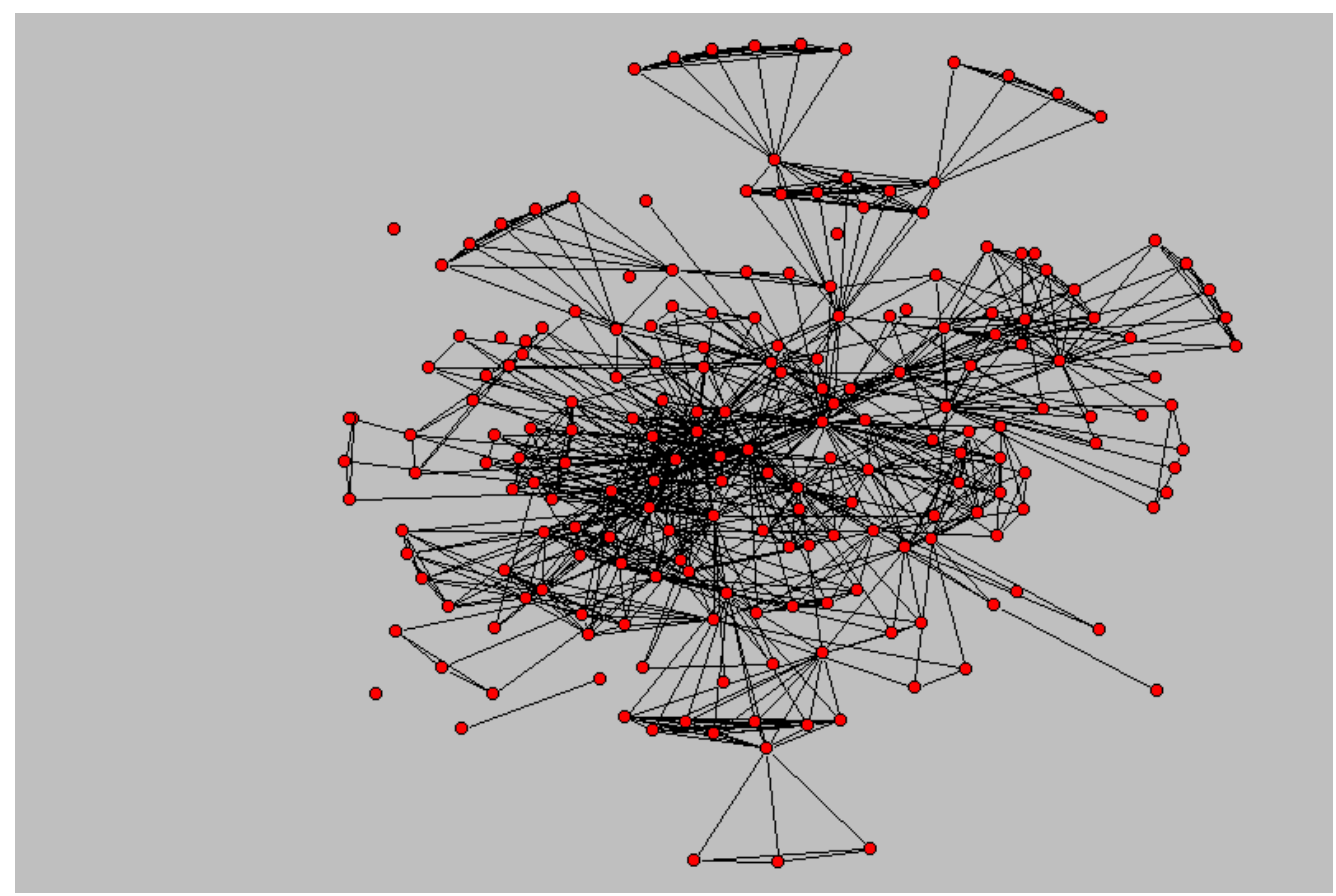

Figura 1: A Rede dos Operadores de ONGs. Fonte: Levantamento direto (2003). 
Em um primeiro olhar, o quadro acima nos sugere uma ampla diversidade dos laços sociais estabelecidos entre os membros componentes desta rede ${ }^{15}$. Há, com efeito, aqueles que mantêm um número bastante significativo de laços e outros que não se relacionam com ninguém (como é o caso dos pontos que se encontram isolados). Existem também, claramente, aqueles que são estratégicos para a formação na rede, centrais e conectando vários atores. São os que controlam recursos, que mobilizam atenções e que provavelmente os que dispõem de um estoque de capital social mais importante; sendo capaz, em traduzir um maior volume de recursos potencialmente mobilizáveis a partir desta posição particular na rede. Esta rede apresenta uma forte diversidade na posição de seus atores; o que resulta em uma densidade média de 0,774 e um desvio padrão de 0,7462. Esta diversidade também é confirmada a partir do alto índice de centralidade16 da rede, $72,87 \%$, com um índice de homogeneidade de apenas 1,51\%. O que indica atores (em número reduzido) bem posicionados na rede, com a conseqüente concentração de poderes em alguns atores. Com efeito, conforme afirma Hanneman (2001:61), “atores que são mais centrais na estrutura, no sentido de terem maior número de conexões, tendem a ter posições mais favoráveis a informações, conseqüentemente, mais poderes". Esta rede apresenta relativamente uma média integração entre seus membros - mesmo considerando as posições diferenciadas de alguns -, o que significa que há um número relativamente importante de tríades e conseqüentemente uma transitividade média. Com efeito, o índice de transitividade17 entre triplos ordenados $\mathrm{i}>\mathrm{j}$ e j -> k é de 46,21\% 18.

\begin{tabular}{|c|c|c|}
\hline N. Participantes & Número de cliques & $\%$ \\
\hline $3-5$ & 52 & 60 \\
\hline $6-7$ & 19 & 22 \\
\hline $8-9$ & 05 & 06 \\
\hline Mais de nove & 11 & 12 \\
\hline
\end{tabular}

Tabela 1: Distribuição das cliques da rede por número de participantes. Fonte: Levantamento Direto

\footnotetext{
${ }^{14}$ Agradeço ao Prof. Klaus Eichner, da Universidade de Hamburgo, pela valiosa ajuda na construção dos indicadores de redes

15 Aqui há que considerar as Instituições onde as pessoas citadas pelos entrevistados estão filiadas. Trata-se, portanto, de uma matriz atores $x$ organizações .

${ }^{16}$ o índice de centralidade é calculado desta forma: "Para uma dada rede binária com vértices V1...vn, e o grau máximo de centralidade cmax, a medida do grau de centralização é $\mathrm{S}(\mathrm{cmax}-\mathrm{c}(\mathrm{vi})$ ) dividido pelo valor máximo possível, onde c(vi) é o grau de centralidade do vértice vi". Borgatti, S.P., Everett, M.G. and Freeman, L.C. 2002. Ucinet 6 for Windows. Harvard: Analytic Technologies.".

17 A Transitividade de uma rede é definida desta forma: "três vértices, u, v e w derivados de um gráfico direto são transitivos se qualquer vértice u é conectado com o vértice v e este é conectado com w".

18 Se considerarmos, entretanto, o índice sem levar em conta a ordem da transitividade, temos $0,14 \%$. Quer dizer, de um total de 8489460 possíveis arranjos entre triplos, encontramos na nossa rede 11706.
} 
Este índice de transitividade - associado ao alto índice de centralidade - indica, entre outras coisas, que há uma assimetria entre os membros da rede no que diz respeito às probabilidades de os participantes da rede em acessarem outros membros. Observamos, desta forma, um número relativamente importante de tríades, mas um relativamente pequeno de atores que concentram fluxos de informações e de poder. A rede se estrutura em campos de sociabilidade onde são relativamente fechados, conectados ao restante do sistema por um ou mais ator, que detém posições privilegiadas. São as cliques, definidas por Wasserman (1994:254) como “Um subgrafo completo composto de três ou mais nódulos. Consiste em um subconjunto de nódulos, todos adjacentes entre si... Podemos considerar a clique enquanto um conjunto de atores que escolheram ficar juntos". As cliques se conectam ao restante da rede, seja de forma simples, com um membro da clique conectando-se aos demais à rede, seja de forma mais complexa com dois ou mais membros da clique encontrando-se em situação multiplexa, participando de mais de uma clique. Neste caso, temos os círculos sociais, ambientes de sociabilidade onde há uma maior proximidade entre os participantes.

A rede de ONGs que estamos examinando é composta de 87 cliques de três ou mais atores, conforme se pode visualizar na tabela 1 . As cliques da nossa rede não são homogêneas. Temos, com efeito, mais da metade das cliques (60\%) é composta com até cinco atores. Não levando em conta os círculos sociais (cliques que se sobrepõem), os atores sociais que se localizam de forma mais centralizada nas cliques maiores são os que detêm mais recursos; aqueles que conectam as suas cliques ao restante da rede também ocupam posição estratégica. A nossa rede, portanto, é composta de sub-redes, com estruturações que variam de simples cliques composta por tríades até vastos campos de sociabilidade construídos a partir de círculos sociais.

Ainda importa assinalar o fato de que esta rede, embora composta por instituições, não representa as posições destas Organizações respectivamente às relações estabelecidas com outros atores. Quer dizer, esta rede não reflete a das Instituições citadas; elas estão representadas simplesmente enquanto campo de sociabilidade dos indivíduos entrevistados. Estas Instituições são o campo de sociabilidade onde as pessoas citadas pelos entrevistados se localizam: locais onde trabalham, onde foram conhecidas, enfim, espaços onde as sociabilidades foram instituídas. Para a reconstrução dos mecanismos de relés sociais importa conhecer as trajetórias de filiação do universo de atores envolvidos: os entrevistados, mas também aqueles que fazem parte da rede dos entrevistados e que mantém de alguma forma conexão com a rede das Instituições acima descritas. Desta forma, 
importa resgatar as diversas trajetórias de sociabilidade, a partir das redes de mediação, de procedência e de destino. Os dados, coletados a partir de entrevistas com pessoas que trabalham em ONGs, nos permitem reconstruir a trajetória das filiações institucionais dos entrevistados, de um lado, e dos membros de suas redes egocentradas, de outro. Estes dois campos de sociabilidade, localizando-se em vêm a formar uma rede maior, composta de 204 Instituições, onde os atores entrevistados e os membros de suas redes egocentradas se localizam.

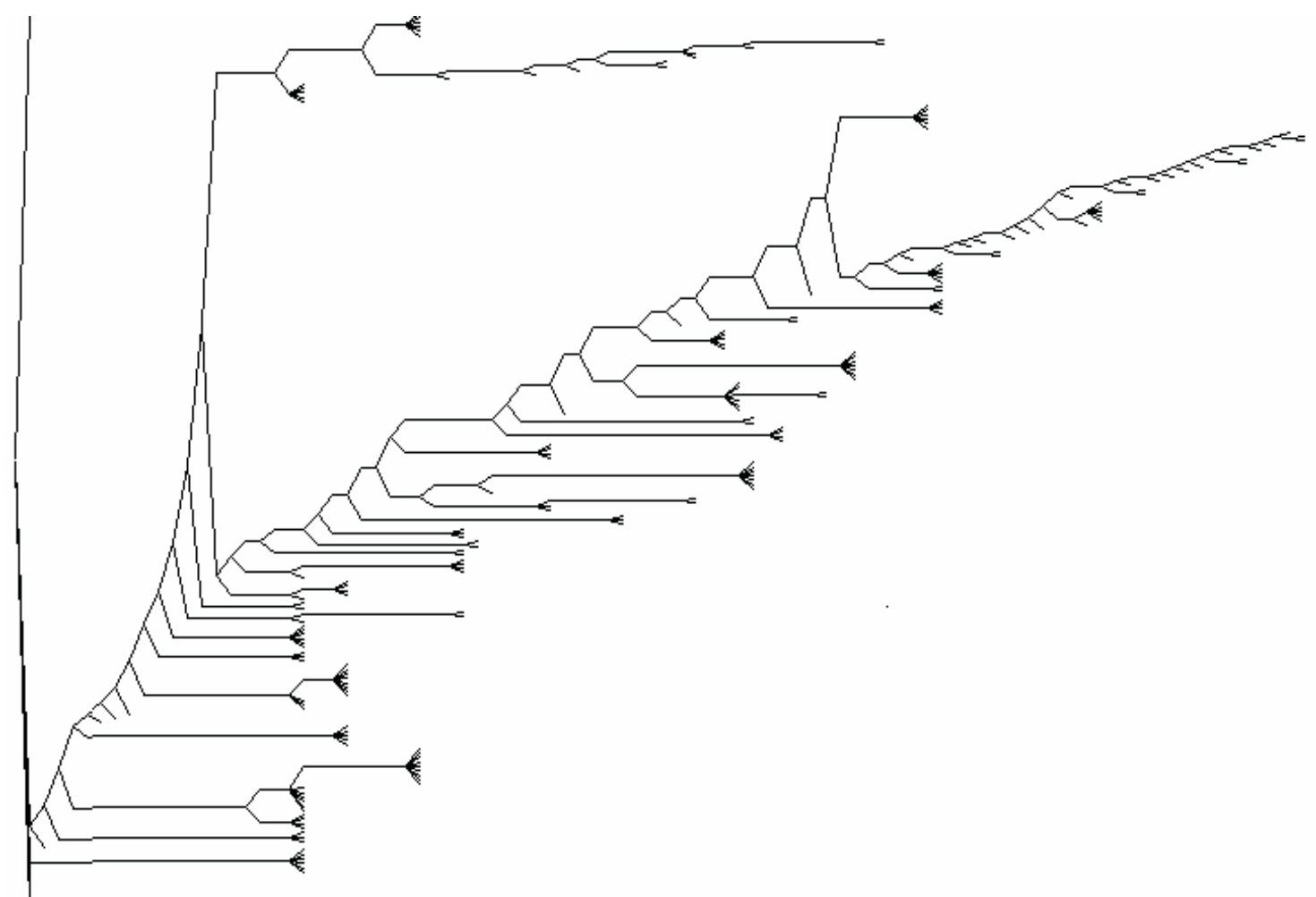

Figura 2: Cluster de cliques de Instituições que fazem parte da rede dos entrevistados. Fonte: levantamento direto.

Fixemos nossa atenção, em primeiro lugar, nos entrevistados. São pessoas que têm idade média entre 35 a 45 anos, em sua maior parte naturais da cidade do Recife, e com escolaridade média de 13 anos Trabalham em média há seis anos e têm rendimento médio mensal de 3,5 salários mínimos. Estas pessoas foram recrutadas principalmente a partir de amigos, isto é, pessoas participantes da rede primária do entrevistado; não obstante o fato de pertencerem à rede pessoal dos entrevistados, parte significativa destas pessoas exerce alguma atividade em alguma ONG: $53,2 \%$ das pessoas que serviram de ponte entre o entrevistado e a ONG onde agora ele trabalha. Mesmo considerando que $33 \%$ destas pessoas são conhecidas a partir do campo de sociabilidade caracterizado por secundário (quer 
dizer, contatos formais), há um número significativo de pessoas pertencentes à rede primária do entrevistado que exerceram alguma atividade em uma ONG. O que talvez possa significar um campo de sociabilidade onde os espaços públicos e privados se entrecruzam, a partir das redes egocentradas de seus participantes, mesmo considerando que $91,5 \%$ dos entrevistados não participaram da fundação da ONG onde trabalham. O que significa que quando foram recrutados, o campo profissional onde eles atuam já estava formado.

\begin{tabular}{|c|c|c|c|}
\hline Tipo de Contato & Num.abs. & \% & \% acumulado \\
\hline Conhecidos & 63 & 67,0 & 67,0 \\
\hline ONGs & 13 & 13,8 & 80,9 \\
\hline Associações Civis & 03 & 3,2 & 86,2 \\
\hline $\begin{array}{c}\text { Instituições } \\
\text { Públicas }\end{array}$ & 02 & 2,1 & 86,2 \\
\hline $\begin{array}{c}\text { Instituições } \\
\text { Privadas }\end{array}$ & 01 & 1,1 & 87,2 \\
\hline Outros & 12 & 12,8 & 100,00 \\
\hline Total & 94 & 100,00 & \\
\hline
\end{tabular}

Tabela 2: Como o entrevistado tomou conhecimento da organização. Fonte: Levantamento Direto.

Passemos agora a investigar os mecanismos de formação das relés. Existem duas possibilidades: (a) relés que se estruturam nas trajetórias de sociabilidade dos entrevistados e que explicam como eles foram recrutados pelas ONGs onde atuam; (b) relés que são ativadas a partir dos campos de sociabilidade formados pelos entrevistados: são campos de sociabilidade onde os entrevistados conhecem pessoas e as recrutam para atuarem em ONGs, seja naquelas onde trabalha ou em outras onde tem contato ${ }^{19}$.

\section{(a) Sobre as trajetórias de sociabilidade: as redes de procedência}

Os entrevistados, como vimos, foram recrutados em sua maioria a partir de conhecimentos localizados na rede de amizades ${ }^{20}$. Parte significativa desta rede é composta de pessoas que atuam profissionalmente em ONGs. As informações que dispomos não nos permitem verificar a trajetória de sociabilidade destas pessoas; as informações indiretas, entretanto, sobre cliques e laços multiplexos, indicadas acima, nos possibilita inferir que também existem campos de sociabilidade por fora das ONGs que são importantes relés para o recrutamento de ONGs. Para o caso dos entrevistados, fica bastante evidente o caso dos partidos políticos. Um dos

\footnotetext{
19 Lembrar o fato de as pessoas que trabalham em ONGs terem uma trajetória profissional onde é freqüente ter atuado em diversas Instituições deste campo profissional. O que resulta em uma rede pessoal onde a presença das pessoas que atuam em ONGs é significativa.

${ }^{20}$ As informações desta parte provêm agora de matrizes de redes egocentradas (atores $\mathrm{x}$ atores)
} 
partidos citados, o Partido dos Trabalhadores, tem uma centralidade destacada na rede, muito acima da centralidade média, que é de 7,819. O PT tem uma centralidade de 13,300, indicando uma importância estratégica21. Muito provavelmente estes dois partidos políticos são importantes relés. O outro campo de sociabilidade importante, o religioso, não apresenta dados de forma tão clara quanto os partidos políticos. Foram citadas várias instituições religiosas e também associações civis ligadas a Instituições Religiosas - como Pastorais e Associações Educativas. O que significa dizer que, em média para as instituições diretamente citadas, não apresentaram centralidade significativa22, mas que de forma alguma não tenham importância enquanto relés. Um outro fato muito interessante é verificar um campo multiplexo de processos de sociabilidade dos entrevistados que ao mesmo tempo são membros dos partidos políticos e que também freqüentam alguma instituição religiosa, como nos mostra a tabela 03 . O que reforça a importância destas duas Instituições entre nossos entrevistados, indicando que, para o caso das ONGs, a trajetória de sociabilidade em Partidos Políticos e Instituições Religiosas é muito importante.

\begin{tabular}{|l|c|c|c|c|}
\hline \multirow{2}{*}{ É membro de Alguma I nstituição Religiosa } & \multicolumn{3}{|c|}{ É membro de algum partido político } \\
\cline { 2 - 5 } & \multicolumn{2}{|c|}{ Sim } & \multicolumn{2}{c|}{ Não } \\
\cline { 2 - 5 } & Num & $\%$ & Num & $\%$ \\
\hline Sim & 25 & 75,75 & 37 & 60,65 \\
\hline Não & 08 & 25,00 & 24 & 39,34 \\
\hline Total & 33 & 100,00 & 61 & 100,00 \\
\hline
\end{tabular}

Tabela 3. Se as pessoas citadas pelo Entrevistado participam de grupo político, por filiação religiosa.

A literatura tem apontado a importância do campo Institucional religioso no recrutamento de militantes para movimentos sociais, partidos políticos e ONGs. Com efeito, como nos mostra Burity (1997):

\footnotetext{
${ }^{21}$ Um outro partido Político, o PC do B (partido Comunista do Brasil), apresenta uma centraldiade de 6,404 .

${ }^{22}$ Somente a Igreja Presbiteriana apresentou umacentralidade maior que a média: 7,882.
} 
Numa pesquisa recentemente concluída, percebemos que a presença de iniciativas religiosas no campo da militância ou assistência social junto a populações carentes é menos incidental do que pareceria dar conta a grande visibilidade das ONGs e os tradicionais enfoques sobre as políticas sociais. Não apenas isto, mas nosso foco sobre o processo de negociação de identidades coletivas impulsionado pelo múltiplo pertencimento (institucional, discursivo, individual) evidenciou uma clara incidência de motivação religiosa nas ações de militantes de ONGs e associações populares.

Temos, desta forma, campos de sociabilidade multiplexos, abrangendo redes de amizade localizadas em associações civis, ONGs, Igrejas e Partidos Políticos. Os dados a respeito de trajetórias de sociabilidade dos entrevistados não nos permitem conclusões definitivas sobre os mecanismos de recrutamento e sobre a importância das relés. Os que apresentaremos a seguir - sobre o processo de recrutamento de operadores de ONGs a partir dos entrevistados, servindo estes e seus campos de sociabilidade enquanto redes de mediação - podem nos oferecer mais detalhes para a compreensão do processo de ativação das relés.

\section{(b) As redes de mediação}

As redes que vamos agora examinar é formada exclusivamente por pessoas que participam de alguma forma de atividades em ONGs, seja como profissionais, voluntários ou simplesmente militantes engajados em alguma campanha. São pessoas que foram citadas pelos entrevistados e que, nas entrevistas, apresentavam duas situações distintas: (a) pessoas que trabalhavam nas ONGs dos entrevistados; (b) pessoas que trabalham em ONGs que não a do entrevistado.

Os mecanismos que ativam as relés serão desvelados a partir de duas variáveis: (a) "capacidade do entrevistado em levar pessoas para trabalharem na sua instituição" e (b) "capacidade do entrevistado em levar pessoas para trabalharem em outras ONGs". Estas duas variáveis serão trabalhadas a partir de tabulações cruzadas segundo atributos dos membros da rede dos entrevistados, de um lado, e filiação a partido político e instituição religiosa, por outro. As duas Instituições selecionadas, partidos e religião, são referência em diversas pesquisas no que diz respeito a conexões que seus membros estabelecem com Associações civis. Os campos institucionais estão centrados nas sociabialidades dos entrevistados, que se põem em contato com pessoas, introduzindo-as no campo profissional das ONGs. As ditas "redes de mediação" - campos institucionais onde se encontram os entrevistados e as pessoas de sua rede egocentrada e de suas relações profissionais - ativam relés. Quer dizer, as pessoas, a partir destes campos de sociabilidade, são remetidas a outros espaços sócio-institucionais. 
Conforme vemos na tabela 04, a rede das pessoas entrevistadas é formada em sua maioria por cinco membros; e a maior parte dos entrevistados cita entre 1 e 4 $\mathrm{ONGs}^{23}$.

\begin{tabular}{|c|c|}
\hline $\begin{array}{c}\text { Numero de ONGs onde atuam } \\
\text { pessoas da rede egocentrada } \\
\text { do entrevistado }\end{array}$ & $\begin{array}{c}\text { Proporção das redes } \\
\text { egocentradas do entrevistado } \\
\text { segundo o número médio de } \\
\text { pessoas da rede }\end{array}$ \\
\hline 1 & $4,3 \%$ \\
\hline 2 & $5,3 \%$ \\
\hline 3 & $7,4 \%$ \\
\hline 4 & $10,6 \%$ \\
\hline 5 & $72,3 \%$ \\
\hline
\end{tabular}

Tabela 4. Descrição das redes do entrevistado segundo proporção média de pessoas na rede e número de ONGs citadas. Fonte: Levantamento direto.

Relativamente à ONG onde trabalha o entrevistado, existem pessoas que lá trabalham e que foram apresentadas pelo entrevistado. O perfil do entrevistado que mais informou que introduzido pessoas no ambiente institucional das ONGs onde trabalha é o seguinte: apresentam em média vários anos de escolaridade, trabalham mais de quarenta horas por semana, trabalhou antes em outra ONG. No que diz respeito ao tipo de relacionamento que mantêm com a pessoa que indicou para trabalhar na ONG, embora a moda da freqüência tenha sido a variável "profissional", as relações de amizade e parentesco não tenham se afastado muito das relações secundárias, o que indica que os laços fortes também são importantes para o recrutamento de quadros para o Terceiro Setor ${ }^{24}$ Mas são laços que, embora possam estar presentes na esfera privada, isto é, tenham um forte conteúdo afetivo, foram construídos no ambiente institucional associativo. Quer dizer, os membros das redes egocentradas dos entrevistados são também militantes de ONGs ou associações civis.

\footnotetext{
${ }^{23}$ Essas ONGs citadas são aquelas descritas mais acima: são as localizações institucionais dos processos de sociabilidade dos entrevistados e de sua rede egocentrada

${ }^{24}$ Como de resto, também se verificou entre os entrevistados: $67 \%$ afirma ter tido conhecimento da ONG onde trabalha através de conhecidos.
} 


\begin{tabular}{|c|c|}
\hline Características do Entrevistado & $\begin{array}{c}\text { Pessoas que o entrevistado levou para } \\
\text { trabalhar em sua ONG }\end{array}$ \\
\hline 14 anos de escolaridade & 2,0 \\
\hline $31-45$ horas de trabalho & 1,52 \\
\hline Trabalhava antes em uma outra ONG & 2,09 \\
\hline $\begin{array}{c}\text { Mantém relacionamento profissional com a pessoa } \\
\text { Tem como o trabalho na ONG a sua atividade } \\
\text { principal }\end{array}$ & 1,0 \\
\hline $\begin{array}{c}\text { Conheceu a Instituição onde trabalha atualmente } \\
\text { através de pessoas que trabalhavam em } \\
\text { Associações Voluntárias }\end{array}$ & 2,67 \\
\hline \begin{tabular}{c} 
Trabalha regularmente com as pessoas indicadas \\
\hline
\end{tabular} & 2,50 \\
\hline
\end{tabular}

Tabela 5: Distribuição da moda do número de pessoas que o Entrevistado levou para trabalhar em sua ONG segundo Características do entrevistado. Fonte: Levantamento direto.

Quando examinamos as pessoas que o entrevistado conhece e que trabalham em outras ONGS (Tabela 06), observamos uma ligeira diferença no perfil dos entrevistados: têm em média uma escolaridade menor, ocupam-se na ONG em tempo parcial (e, consequentemente, não têm na ONG a sua atividade principal). Há, entretanto, um fato comum bastante significativo. Os entrevistados conheceram estas pessoas também a partir de campos de sociabilidade localizados em Associações voluntárias. O que demonstra uma trajetória de sociabilidade comum - e provavelmente círculos sociais multiplexos - destes dois grupos de conhecidos dos entrevistados (os que trabalham em suas ONGs e os que trabalham em outras ONGS).

\begin{tabular}{|c|c|}
\hline Características do entrevistado & $\begin{array}{c}\text { Pessoas que o entrevistado conhece em outra } \\
\text { ONG }\end{array}$ \\
\hline 10 Anos de escolaridade & 3,0 \\
\hline $\begin{array}{c}\text { Carga horária de trabalho semanal entre 16-30 } \\
\text { horas }\end{array}$ & 1,2 \\
\hline Não é atividade principal & 1,19 \\
\hline Trabalhou antes em Instituição Pública & 1,14 \\
\hline $\begin{array}{c}\text { Tomou conhecimento da Organização através de } \\
\text { Associações Civis }\end{array}$ & 2,33 \\
\hline
\end{tabular}

Tabela 6: Pessoas da rede egocentrada do Entrevistado que trabalha em outras ONGs por características do entrevistado. Fonte: levantamento direto. 
Embora, como percebemos na tabela 07, o número de pessoas que o entrevistado conhece e que foram recrutadas para sua ONG seja menor que aquelas que ele conhece em outras ONGs, as informações que dispomos nos permitem afirmar que há um campo de sociabilidade bastante visível entre os entrevistados, que está presente em seus laços primários e secundários; que, de certa forma, estrutura a suas trajetórias profissionais ${ }^{25}$.

\begin{tabular}{|c|c|c|}
\hline $\begin{array}{c}\text { Numero de Pessoas } \\
\text { Conhecidas pelo entrevistado }\end{array}$ & $\begin{array}{c}\text { Proporção de pessoas que o } \\
\text { entrevistado levou para } \\
\text { trabalhar em sua ONG }\end{array}$ & $\begin{array}{c}\text { Proporção de pessoas que o } \\
\text { entrevistado conhece em } \\
\text { outras ONGs }\end{array}$ \\
\hline 0 & 58,5 & 50,0 \\
\hline 1 & 16,0 & 30,9 \\
\hline 2 & 8,5 & 12,8 \\
\hline 3 & 7,4 & 1,1 \\
\hline 4 & 3,2 & 4,3 \\
\hline 5 & 6,4 & 1,1 \\
\hline
\end{tabular}

Tabela 07: Proporção de pessoas que o entrevistado conhece e que levou para trabalhar em sua ONG e proporção de pessoas que o entrevistado conhece em outras ONGs. Fonte: Levantamento direto.

Finalmente, algumas considerações sobre os campos de sociabilidade onde são ancoradas as relés sociais. Como mostramos acima, há uma importância muito expressiva dos partidos políticos e das Instituições religiosas na trajetória profissional dos entrevistados. E também um entrecruzamento de círculos sociais, o do campo religioso e o político. Este fato tem importante repercussões nas redes de ONGs dos entrevistados. Com efeito, como nos mostra a tabela 8, o pertencimento a um grupo religioso ou partido político é uma variável importante na explicação dos membros das redes dos entrevistados. Aqueles que foram recrutados para as ONGs dos entrevistados são em maior número (1,45 em média) entre os que participam do mesmo grupo religioso do entrevistado; o mesmo em relação à participação em partidos políticos $(2,15$ em média para as pessoas que participaram). O mesmo fato se repete em relação aos conhecidos dos entrevistados que trabalham em outras ONGS que não a do entrevistado, onde em média 3,61 pessoas pertencem a um grupo religioso e 1,31 pessoas já foram membros de um partido político.

\footnotetext{
${ }^{25}$ Podemos inferir que, da mesma forma que o entrevistado recruta pessoas de seu círculo, ele também pode ser sido recrutado em outras ocasiões; ou mesmo, em uma perspectiva futura, ele com certeza acionará suas redes para colocações profissionais.
} 


\begin{tabular}{|l|c|c|c|c|c|c|}
\hline \multirow{2}{*}{$\begin{array}{l}\text { Característica } \\
\text { da relé }\end{array}$} & \multicolumn{3}{|c|}{ Grupo Religioso } & \multicolumn{3}{c|}{ Partido Político } \\
\cline { 2 - 7 } & Pertence & $\begin{array}{c}\text { Já } \\
\text { Pertenceu }\end{array}$ & $\begin{array}{c}\text { Nunca } \\
\text { Pertenceu }\end{array}$ & Participa & $\begin{array}{c}\text { Já } \\
\text { Participou }\end{array}$ & $\begin{array}{c}\text { Nunca } \\
\text { Participou }\end{array}$ \\
\hline $\begin{array}{l}\text { Recrutamento de } \\
\text { membros para } \\
\text { sua ONG }\end{array}$ & 0,39 & 1,45 & 1,16 & 0,67 & 2,15 & 1,25 \\
\hline $\begin{array}{l}\text { Conhecidos em } \\
\text { outras ONGs }\end{array}$ & 3,61 & 2,16 & 3,41 & 0,15 & 1,31 & 0,95 \\
\hline
\end{tabular}

Tabela 8: Relés sociais ativadas a partir de grupos políticos e religiosos. Fonte: levantamento direto

Fato também importante, embora menos significativo, é a presença na rede de pessoas das relações sociais primárias dos entrevistados que também estão colocadas profissionalmente em ONGs citadas pelos entrevistados, seja aquelas onde eles trabalham, seja em outra ONG. Como nos mostra a tabela abaixo, há uma presença mais importante de parentes e amigos que pessoas que mantêm com o entrevistado relações estritamente profissionais. Embora menos importante, o campo das sociabilidades primárias também se estrutura enquanto relé, enquanto alavancadora das trajetórias profissionais dos operadores das Organizações Não Governamentais.

\begin{tabular}{|l|l|l|l|l|l|l|l|l|}
\hline $\begin{array}{c}\text { Característica da } \\
\text { Relé }\end{array}$ & \multicolumn{2}{|c|}{$\begin{array}{c}\text { Número médio de } \\
\text { pessoas que são } \\
\text { Parentes do } \\
\text { entrevistado }\end{array}$} & \multicolumn{2}{c|}{$\begin{array}{c}\text { Número médio de } \\
\text { pessoas que são } \\
\text { amigas do } \\
\text { entrevistado }\end{array}$} & \multicolumn{2}{|c|}{$\begin{array}{c}\text { Número médio de } \\
\text { pessoas que têm } \\
\text { relação profissional } \\
\text { com o entrevistado }\end{array}$} \\
\cline { 2 - 9 } & $\mathbf{1}$ & $\mathbf{2}$ & $\mathbf{3}$ & $\mathbf{1}$ & $\mathbf{2}$ & $\mathbf{3}$ & $\mathbf{1}$ & $\mathbf{2}$ \\
\hline $\begin{array}{l}\text { Recrutamento de } \\
\text { membros para sua } \\
\text { ONG }\end{array}$ & 1,16 & 1,11 & 0,64 & 0,61 & 0,92 & 1,42 & 1,14 & 0,52 \\
\hline $\begin{array}{l}\text { Conhecidos } \\
\text { outras ONGs }\end{array}$ & 0,71 & 1,0 & 0,68 & 0,64 & 1,08 & 0,81 & 0,86 & 0,67 \\
\hline
\end{tabular}

Tabela 9: Relés sociais ativadas a partir de Redes de laços fortes. Fonte: levantamento direto.

\section{Conclusões}

Os resultados acima apresentados nos informam sobre uma situação bastante particular: a de campos de sociabilidade estruturados entre operadores de Organizações não governamentais que atuam na área de educação na cidade do Recife. Os dados não permitem, portanto, nenhuma generalização. Acredito que a contribuição mais importante deste artigo é o de mostrar a possibilidade de instrumentalizar empiricamente um conceito, o de relé social, que introduz questões relativamente não exploradas na literatura sobre Organizações Não Governamentais e Associações Voluntárias. 
O conceito de relé aqui utilizado foi concebido por Ohlemacher para explicar processos de mobilização de recursos em movimentos sociais. A engenhosa idéia, como mostramos acima, estava presente implicitamente na literatura sobre mobilização coletiva, e mesmo na teoria clássica, a partir da idéia de círculo social desenvolvida por Simmel. Mas a literatura consultada não indicava como trabalhar o conceito empiricamente. Quer dizer, quais são os procedimentos a adotar para investigarmos a formação dos círculos sociais e a ativação das relés em um campo de sociabilidade particular, por exemplo, o das Organizações Não Governamentais?

A idéia de relé social nos permite que introduzamos mais um ingrediente na análise das associações voluntárias: que, embora não desconsiderando as variáveis pertencentes aos atributos individuais e suas inserções estruturais (classe, etnia, região/nação), a forma como as pessoas estruturam suas práticas, construindo suas redes, também explica suas trajetórias de sociabilidade; no nosso caso, também explica como estas estruturações de redes formam campos sociais mais amplos, com uma lógica de funcionamento oriunda destas práticas sociais. Podemos, desta forma, pensar que há particularidades nas estruturações de redes, por exemplo, de operadores de ONGs.

Indicamos algumas pistas, como por exemplo, o fato da importância dos círculos sociais religiosos e dos partidos enquanto relés que ativam inserções dos indivíduos em ONGs. Este fato não é novidade, posto que diversos estudos empíricos apontaram a importância destes campos de sociabilidade para a formação das ONGs na América Latina. Principalmente após a vaga autoritária que varreu o continente na década de 60, com a desestruturação dos Partidos Políticos de esquerda, seus militantes se abrigam nos movimentos populares apoiados pela Igreja Católica Progressista, em um primeiro momento. Depois, com a redemocratização, voltam os partidos de esquerda. Permanece, entretanto, esta estreita superposição de campos de sociabilidade, o dos partidos de esquerda, os da Igreja Progressista ${ }^{26}$.

O que julgo importante é que propomos uma nova abordagem no estudo deste fenômeno, que, com os recursos da informática e das construções de softwares que permitam a manipulação de dados de redes em maior escala, é possível construir instrumentos empíricos que permitam uma visualização mais acurada deste fenômeno. O que antes trabalhávamos apenas de forma intuitiva é agora passível 
de ser formalizado empiricamente em protocolos de pesquisa mais precisos, mais fiáveis. Não se trata, evidentemente, de recurso metodológico que pretenda substituir todos os outros27, mas de acrescentar um que introduz, creio, com sucesso, respostas empíricas para questões já formuladas há algum tempo.

\section{Bibliografia}

Alba, Richard D., Gwen Moore (1978). "Elite social circles". Sociological Methods and Research 7, № 2 (nov): 167-187.

Barnes, J.A. (1987). "Redes Sociais e Processo Político". En: A Antropologia das Sociedades Contemporâneas. Bela Feldman-Bianco, org. São Paulo: Global, 159192.

Baron, James; Joel P. (1997). "Resources and relationships: social networks and mobility in the workplace", American Sociological Review 62:673-693.

Bian, Yanjie (1997). "Bringing strong ties back in: indirect ties, network bridges, and job searches in China", American Sociological Review 62 (june): 366-385.

Boissevain, Jeremy (1976). Friends of Friends. Networks, manipulators and coalition. Oxford: Blackwell, p. 152

Bourdieu, P. (1994). Distinction. A Social Critique of the judgement of taste. London: Routledge.

Bratton, Michael (1999). "Political participation in a new democracy". Comparative Political Studies 32, № 5 (aug): 549-588.

Burity, Joanildo (1997). "Cultura e Identidade no campo religoso". In: http://bibliotecavirtual. clacso.org.ar/ar/libros/brasil/cpda/estudos/nove/burity9.htm

Castells, Manuel (1997). The information Age. Economy, society and culture (Volume II: The power of identity). Malden, MA: Blackwell publishers.

Coser, Lewis (1965). Georg Simmel. Englewood Cliffs, NJ : Prentice Hall Inc.

\footnotetext{
${ }^{26}$ Embora a Igreja Católica, com a Teologia da Libertação seja a mais visível, há também movimentos sociais oriundos de outras denominações religiosas.

${ }^{27}$ Até porque para algumas questões a metodologia de redes não se mostra adequada.
} 
Cress, Daniel Msnow; David A. (1996). "Mobilization at the margins: Resources, benefactors, and the viability of homeless social movement organizations". American Sociological Review 61, № 6 (dec): 1089-1109.

Diani, Mario (1978). Linking mobilizations frames and political opportunities: Insights from regional populism in Italy.

Fischer, Claude (org.) (1977). Networks and places. Social relations in the urban setting. New York: The Free Press.

Fontes, Breno Augusto Souto Maior (2004). “Capital Social e Terceiro Setor: sobre a estruturação das redes sociais em associações voluntárias". En: Breno Martins Fontes, Paulo Henrique. Redes Sociais e Saúde. Novas possibilidades teóricas. Recife: Editora da UFPE.

Fontes, Breno Augusto Souto Maior.(2004a). "Sobre Trajetórias de Sociabilidade: a idéia de relé social como mecanismo criador de novas redes sociais", Revista de Sociologia e Política. Florianópolis, v. 1, n. 5, p. 55-76

Forsé, Michel, Alain Degenne (1999). Introducing social networks. London, Sage Publications.

Galaskiewicz, Joseph (1994). Advances in social network analysis. London, Sage Publications.

Granovetter, Mark (1995). Getting a J ob. A study of contacts and careers. 2nd. ed. Chicago: The University of Chicago Press.

Gould, Roger V. (1993). "Trade cohesion, class unity, and urban inssurection: Artisanal activism in the Paris Commune". AJS 98, № 4 (jan): 721-754.

Gould, Roger V. (1993). "Collective action and network structure". American Sociological Review 58: 182-196.

Habermas, Jürgen (1996). Between facts and norms. Contributions to a discourse theory of law and democracy. Cambridge, MA: The MIT Press.

Hedström, Peter, Rickard Sandell, Charlotta Stern (2000). “Mesolevel Networks and the diffusion of social movements: the case of the Swedish Social democratic party". AJS 106: 145-172. 
Ingram, Paul, Peter Roberts (2000). "Friendships among competitors in the Sidney hotel industry". AJS 106: 387-423.

Johnson; Jeffrey C. (1994). "Anthropological contributions to the study of social networks". En: Stanley Wasserman, Joseph Galaskiewicz. Advances in Social Network Analysis. London: Sage Publications.

Keister, Lisa A. (2001). "Exchange structures in lending and trade relations in chinese business groups", American Sociological Review 66: 336-360.

Kin, Hyjoung, Peter Bearman (1997). "The structure and dynamics of movement participation", American Sociological Review Vol. 62 (june): 70-92.

Klandermans, Bert (1984). “Mobilization and participation: social psychological expansions of resource mobilization theory", American Sociological Review 49: 583600.

Kogut, Bruce, Gordon Walker (2001). "The small world of germany and the durability of national networks", American Sociological Review 66: 317-335.

Lee, Barret A., Karen E. Campbell (1999). "Neighbor networks of black and white Americans". En: Barry Wellman. Networks in the global Village. Life in contemporary communities. Boulder, CO: Westview Press, 119-146.

McAdam, Doug (1986). "Recruitment to high-risk activism: the case of freedom summer". AJS 92, № 1 (july): 64-90.

Marwell, Gerald, Pamela Oliver (1993). The critical mass in collective action. A micro-social theory. New York: Cambridge University Press.

McPherson, J. Miller, Pamela Popierlarz (1992). "Social networks and organizational dynamics", American Sociological Review 57: 153-170.

Melucci, Alberto (1996). Challenging codes: collective action in the information age. New York: Cambridge University Press.

Ohlemacher, Thomas (1999). “Brücken der Mobilisierung. Soziale Relais und persönliche Netzwerke in Bürgerinitiativen gegen militärischen tie flug". Hamburg. Unpublished manuscript. 
Ohlemacher, Thomas (1999a). "Struktur und System. Eine Empiriebasierte Annäherung von Strukturaler Analyse und Systemtheorie". Habilitationsschrift an der Universität Hamburg.

Oliver, Pamela, Daniel J. Myers (2000). “Networks, Diffusion and Cycles of Collective action". Paper prepared for Social Movement Analysis: The Network Perspective, a workshop held at Ross Priory, Loch Lomond, Scotland, june 22-25.

Panfichi, Aldo (1997). "Networks and identities among urban poor in Lima, Peru". LASA 97, XX International Congress, Guadalajara, Mexico. Painel POL41: Networks and Political culture. Argentina, Brazil and Peru.

Passy, Florence (2000). "Socialization, recruitment, and the structure/agency gap. A specification of the impact of networks on participation in social movements". Paper prepared for Social Movement Analysis: The Network Perspective, a workshop held at Ross Priory, Loch Lomond, Scotland, june 22-25.

Popierlarz, Pamela, J. Miller McPherson (1995). "On the Edge or in Between: niche position, niche overlap, and the duration of voluntary associations memberships". AJS Vol. 101, № 3 (nov): 698-720.

Pescosolido, Bernice, Beth Rubin (2000). "The web of group affilitation revisited: social life, postmodernism and sociology", American Sociological Review 65: 52-76.

Scherrer-Warren, Ilse (1996). "ONG: os novos atores da 'Aldeia Global'”. Paper apresentado no GT01, Cidadania, Conflito e Transformações Urbanas na XX Reunião Anual da ANPOCS, Caxambu, MG, out.

Sampell, Rickard, C. Stern (1998). "Group size and the logic of collective action. A network analysis of a Swedish temperance movement. 1896-1937". Rationality and Society 10, № 3 (aug): 327-345.

Sampson, Robert (1991). “Linking the micro and macrolevel dimensions of community social organization". Social Forces, 70 (1): 43-64.

Simmel, Georg (1991). The philosophy of money. London: Routledge.

Simmel, Georg (1993). "Sociabilidade: um exemplo da sociologia pura ou formal". En: Georg Simmel. Sociologia/organizador [da coletânea] Evaristo de Morais Filho. São Paulo: Ática, 165-181. 
Simmel, Georg (2000). Sociologie. Etudes sur les formes de la socialization. Paris: PUF.

Snow, David, Louis Zurcher J r. (1980). "A social networks and social movements: a microstructural approach to differential recruitment", American Sociological Review 45 (oct) : 787-801.

Smith, Steven Rathgeb, Michael Lipsky (1994). Non profits for hire. The welfare state in the age of contracting. Cambridge, MA: Harvard University Press.

Tarrow, Sydney (1994). Power in movement: Social movements, collective action, and politics. Cambridge: Cambridge University Press.

Tolbert, Charles M., Thomas A. Lyson, Michael Irwin (1998). “Local capitalism, civic engagement and socioeconomic well-being", Social Forces 77(2): 401-28.

Verba, Sidney, Kay Lehman Scholozman, Henry Brady (1998). Voice and equality: civic voluntarism in American Politics. Cambridge, MA: Harvard University Press.

Wellman, Barry (1983). "Network analysis: some basic principles". In: Wellman, Barry, ed. Sociological theory. 155-200.

Wuthnow, Robert (1998). Loose connections. Joining together in America's fragmented communities. Cambridge, MA: Harvard University Press. 